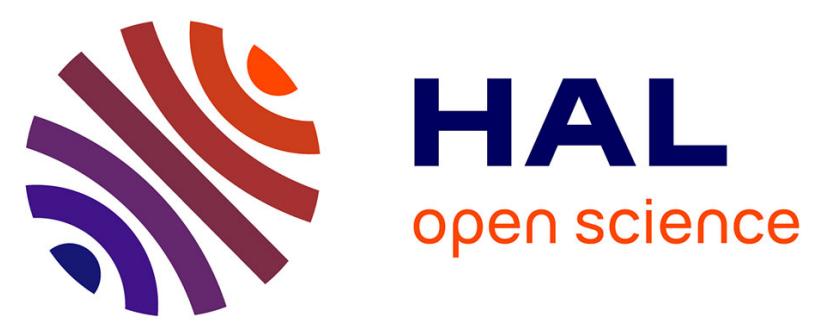

\title{
Charge injection mitigation in polyethylene induced by silver nanoparticles containing organosilicon barrier layer as demonstrated by conductivity measurements
}

Laurent Millière, Kremena Makasheva, Christian Laurent, Bernard Despax, Laurent Boudou, G. Teyssedre

\section{To cite this version:}

Laurent Millière, Kremena Makasheva, Christian Laurent, Bernard Despax, Laurent Boudou, et al.. Charge injection mitigation in polyethylene induced by silver nanoparticles containing organosilicon barrier layer as demonstrated by conductivity measurements. 2016 IEEE Nanotechnology Materials and Devices Conference (NMDC), Oct 2016, Toulouse, France. pp.1-2, 10.1109/NMDC.2016.7777172 . hal-02324446

\section{HAL Id: hal-02324446 \\ https://hal.science/hal-02324446}

Submitted on 1 Nov 2019

HAL is a multi-disciplinary open access archive for the deposit and dissemination of scientific research documents, whether they are published or not. The documents may come from teaching and research institutions in France or abroad, or from public or private research centers.
L'archive ouverte pluridisciplinaire HAL, est destinée au dépôt et à la diffusion de documents scientifiques de niveau recherche, publiés ou non, émanant des établissements d'enseignement et de recherche français ou étrangers, des laboratoires publics ou privés. 


\title{
Charge injection mitigation in polyethylene induced by silver nanoparticles containing organosilicon barrier layer as demonstrated by conductivity measurements*
}

\author{
L. Milliere, K. Makasheva, Member IEEE, C. Laurent, Fellow IEEE, B. Despax, L. Boudou, \\ G. Teyssedre, Member IEEE
}

\begin{abstract}
Injection mitigation in low density polyethylene (LDPE) films by plasma processed silver nanoparticles (AgNPs) containing plasma polymer composites was recently reported through space charge measurements. The barrier effect to charge injection has been assigned to the creation of permanent deep traps by introducing silver nanoparticles near the polyethylene surface. For completeness, current measurements realized on LDPE films with and without AgNPs have been carried out. Presence of the composite layers reduces the current density by one order of magnitude. These results strengthen the interpretation of the barrier effect based on space charge stabilized by deep traps formed by the AgNPs.
\end{abstract}

\section{INTRODUCTION}

Main challenge in the development of HVDC polymeric insulation is to avoid the accumulation of space charge under electrical and/or thermal stresses which can significantly reduce the component reliability $[1,2]$ owing to excursions in the internal electric fields beyond the design field, triggering electrical damages $[3,4]$. One promising strategy to decrease the amount of space charge is to limit the source of electronic carriers provided by injection at the electrodes. Actually, only few studies focus on the polymer/electrodes interface properties to tune the charge injection effect. The most common studies consist in modification of the polymer sample interface by fluorination with a $\mathrm{F}_{2} / \mathrm{N}_{2}$ mixture [5]. Charge injection mitigation was suggested to be due to the presence of deep traps into the fluorinated layer that can block or shield further charge injection [6].

By following a strategy to introduce deep permanent traps near the surface in controlled way, we have recently reported $[7,8]$ on a very efficient method for charge injection mitigation when a thin nanocomposite layer (50 $\mathrm{nm}$ thick) containing silver nanoparticles (AgNPs) embedded in organosilicon matrix is deposited on the surface of a polyethylene sample. This was achieved by investigating space charge patterns. Whereas positive charges dominate the patterns obtained on bare LDPE, no space charge build-up was detected within the bulk of the insulation with tailored interfaces, for applied fields up to $50 \mathrm{kV} / \mathrm{mm}$. The proposed mechanism for such behavior is the ability of AgNPs to store charges, thus playing the role of permanent deep traps for the injected charges. In the following, we complete the study considering conductivity measurements achieved on the LDPE with tailored interfaces.

*Research supported by Agence Nationale de la Recherche, France, project ANR-InTail under Contract No. ANR-AA-PBLI-II-2011

The authors are with Laboratory on Plasma and Energy Conversion, LAPLACE, University of Toulouse, CNRS, INPT, UPS, France.

\section{RESULTS AND DISCUSSION}

\section{A. Material processing}

The nanocomposite layer used for tailoring LDPE interfaces consists of $\mathrm{AgNPs} / \mathrm{SiO}_{\mathrm{x}} \mathrm{C}_{\mathrm{y}}: \mathrm{H}$ stack. The deposition was performed in two-step process: silver sputtering to obtain the single layer of AgNPs followed by plasma polymerization to create the dielectric cover matrix [9]. For both steps, we have used an axially-asymmetric RF (13.56 MHz) capacitively-coupled discharge maintained at low gas pressure [10].

The results given in this work are for sputtering time of $5 \mathrm{~s}$ for a plasma maintained in pure argon at pressure of $\mathrm{p}=8.0 \mathrm{~Pa}$ with $\mathrm{RF}$ power of $\mathrm{P}=40 \mathrm{~W}$ which induces a selfbias voltage of $\mathrm{V}_{\mathrm{dc}}=-725 \mathrm{~V}$ on the powered (smaller) electrode to perform the sputtering. The processed dielectric layer to cover the AgNPs is a plasma organosilicon deposit $\left(\mathrm{SiO}_{\mathrm{x}} \mathrm{C}_{\mathrm{y}}: \mathrm{H}\right)$ obtained in the same reactor with argonhexamethyldisiloxane (HMDSO, $\left[\mathrm{CH}_{3}\right]_{6} \mathrm{Si}_{2} \mathrm{O}$ ) mixture at total gas pressure of $\mathrm{p}_{\text {tot }}=6.6 \mathrm{~Pa}$ and input power of $\mathrm{P}=80 \mathrm{~W}$ $\left(\mathrm{V}_{\mathrm{dc}}=-900 \mathrm{~V}\right)$. These plasma conditions result in deposition of large and isolated AgNPs, of $15 \mathrm{~nm}$ of average size and surface density of $6.1 \times 10^{11} \mathrm{~cm}^{-2}$ (see Fig. 1) embedded in organosilicon matrix with insulating properties of $50.0 \mathrm{~nm}$ total thickness to form the nanocomposite layer. Details on the structural characterization of the obtained nanocomposites are given elsewhere [7, 8].

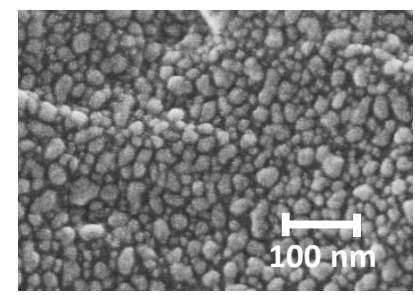

Fig. 1 : SEM images in plan-view of the AgNPs layer deposited on LDPE substrate

For current measurement purposes, additive-free LDPE films, $300 \mu \mathrm{m}$ in thickness and $70 \mathrm{~mm}$ in diameter, processed by press-molding at $155^{\circ} \mathrm{C}$, were used [8]. The two faces of the LDPE sample were tailored with identical nanocomposite layers. Current-voltage measurements on bare LDPE and on tailored LDPE samples are compared. In both cases, SC electrodes (polyethylene doped with carbon black) of $30 \mathrm{~mm}$ diameter (and $350 \mu \mathrm{m}$ thickness) were in contact with the sample. 


\section{B. Impact of tailored interface on the apparent conductivity of $L D P E$}

Fig. 2 shows the current-voltage plots obtained at room temperature for bare LDPE and for two-face tailored LDPE. In both cases, the electrode in contact with the sample is a semiconducting material, i.e. the same configuration as for the space charge measurements [8]. As can be observed, there is a substantial difference in the behaviour of the two samples. First, a quantitative difference, with a drop of the apparent conductivity by about one decade in the sample with tailored interfaces, in the high field range. Second, there is a qualitative difference through a change in the slope of the current-voltage characteristic from to 2 to almost 1, i.e. from what seems relevant from a space charge limited current to a behaviour featuring ohmic conductivity.

From these conductivity results, the injection mitigation effect by the tailored interfaces can be confirmed and substantiated. The SC/LDPE interface (without nanocomposite layer) provides very efficient injection, particularly for positive carriers, and also for negative carriers if compared to Aluminum electrode for example [8, 11]. In such situation, positive space charge builds up adjacent to the positively biased electrode, and an equilibrium situation is reached between the flux of injected carriers and their transport in the insulation. The injection flux is modulated by a decrease of the electrode field, a process in line with the square dependence of the conduction with field. The conduction behaviour changes drastically when the interface is tailored with the $\mathrm{AgNPs} / \mathrm{SiO}_{\mathrm{x}} \mathrm{C}_{\mathrm{y}}: \mathrm{H}$ stack. With injection mitigation by forming artificial traps, the amount of carriers, whether they escape from the traps or cross the barrier due to traps saturation is substantially reduced and space charge limitation is no more at play. A field reduction at the electrode of up to $50 \mathrm{kV} / \mathrm{mm}$ can be produced with the achieved high density of AgNPs, and supposing that every nanoparticle is able to accommodate at least one elementary charge. The insulating organosilicon matrix that embeds the AgNPs ensures the storage effect by blocking the charges not to escape the AgNPs. Current results are in line with charge transport models relevant to LDPE [12] on the fact that holes appear as the dominant electronic carriers in PE. Moreover, the efficiency of the tailored interfaces was demonstrated in case of negative carriers as well [8].

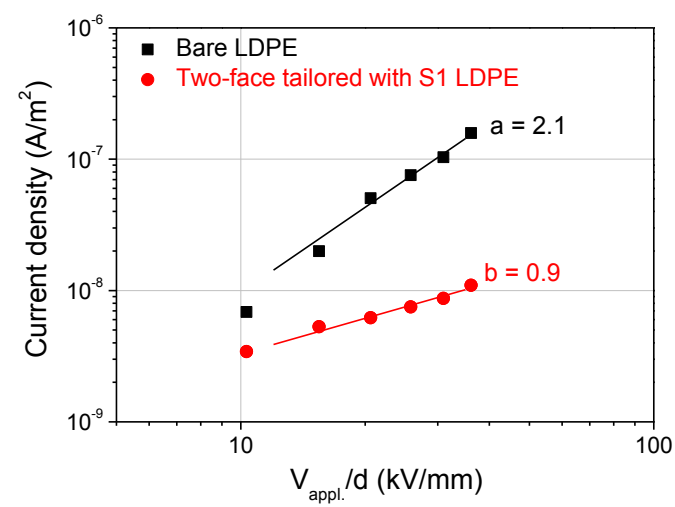

Fig. 2. Current-field plot obtained for reference LDPE and LDPE with tailored interfaces using SC electrodes. Data are relevant to charging current after $16 \mathrm{~min}$ of polarization.

\section{CONCLUSION}

Charge injection mitigation in low density polyethylene films by plasma processed AgNPs containing organosilicon plasma polymer, recently reported through space charge measurements was reconsidered in the light of charging current measurements. With two-face tailored LDPE layers, a strong decrease of the apparent conductivity is observed and a change in the conduction regime from space-charge limited to ohmic conduction is revealed. These results strengthen the interpretation of the barrier effect based on space charge stabilized by deep traps formed by the AgNPs embedded in insulating plasma polymer matrix.

\section{REFERENCES}

[1] G. Mazzanti and M. Marzinotto "Extruded Cables for High-Voltage Direct-Current Transmission: Advances in Research and Development" (Wiley-Blackwell: New York), 2013.

[2] T. L. Hanley, R. P. Burford, R. J. Fleming, and K. W. Barber "A general review of polymeric insulation for use in HVDC cables" IEEE Electr. Insul. Mag., vol. 19, pp. 13-24, 2003.

[3] G. C. Montanari and P. H. F. Morshuis "Space charge phenomenology in polymeric insulating materials" IEEE Trans. Dielectr. Electr. Insul., vol. 12, pp. 754-767, 2005

[4] C. Laurent, G. Teyssedre, S. Le Roy and F. Baudoin "Charge dynamics and its energetic features in polymeric materials" IEEE Trans. Dielectr. Electr. Insul., vol. 20, pp. 357-381, 2013.

[5] Z. An, Q. Yang, C. Xie, Y. Jiang, F. Zheng, and Y. Zhang "Suppression effect of surface fluorination on charge injection into linear low density polyethylene" J. Appl. Phys., vol. 105, p. 064102 , 2009

[6] $\mathrm{Ni}$ Zhao, Yongjie Nie, Shengtao $\mathrm{Li}$ et al. "Space Charge Characteristics of Low Density Polyethylene Oxyfluorinated with High Concentrations of Oxygen" 11th International Conference on Properties and Applications of Dielectric Materials, Sydney, Australia, July 19-22, 2015.

[7] .L. Milliere, K. Makasheva, C. Laurent, B. Despax, and G. Teyssedre "Efficient barrier for charge injection in polyethylene by silver nanoparticles/plasma polymer stack" Appl. Phys. Lett., vol. 105, p. $122908,2014$.

[8] L. Milliere, K. Makasheva, C. Laurent, B. Despax, L. Boudou, and G. Teyssedre "Silver nanoparticles as a key feature of a plasma polymer composite layer in mitigation of charge injection into polyethylene under dc stress" J. Phys. D: Appl. Phys., vol. 49, p. 015304, 2016.

[9] K. Makasheva, C. Villeneuve-Faure, S. Le Roy, B. Despax, L. Boudou, C. Laurent, and G. Teyssedre "Silver nanoparticles embedded in dielectric matrix: charge transport analysis with application to control of space charge formation" Proc. IEEE Conference on Electrical Insulation and Dielectric Phenomena, Shenzhen, China, pp. 238-241, 2013.

[10] B. Despax and P. Raynaud "Deposition of "Polysiloxane" Thin Films Containing Silver Particles by an RF Asymmetrical Discharge" Plasma Process. Polym., vol. 4, pp. 127-134, 2007.

[11] C. Xiao, Y. Zhang, Z. An, F. Zheng, W. Wei, and H. Xuan "Interface electric field of carbon black loaded electrode and its significant influence on charge injection into polyethylene" J. Appl. Polym. Sci., vol. 123, pp. 3017-3022, 2012.

[12] S. Le Roy, G. Teyssedre, C. Laurent, G. C. Montanari, and F. Palmieri "Description of charge transport in polyethylene using a fluid model with a constant mobility: fitting model and experiments" J. Phys. D: Appl. Phys., vol. 39, pp.1427-1436, 2006. 